\title{
Mixed Stone
}

National Cancer Institute

\section{Source}

National Cancer Institute. Mixed Stone. NCI Thesaurus. Code C35585.

A concretion in the body that is composed of more than one substance. 